\title{
Auf die Performance kommt es an
}

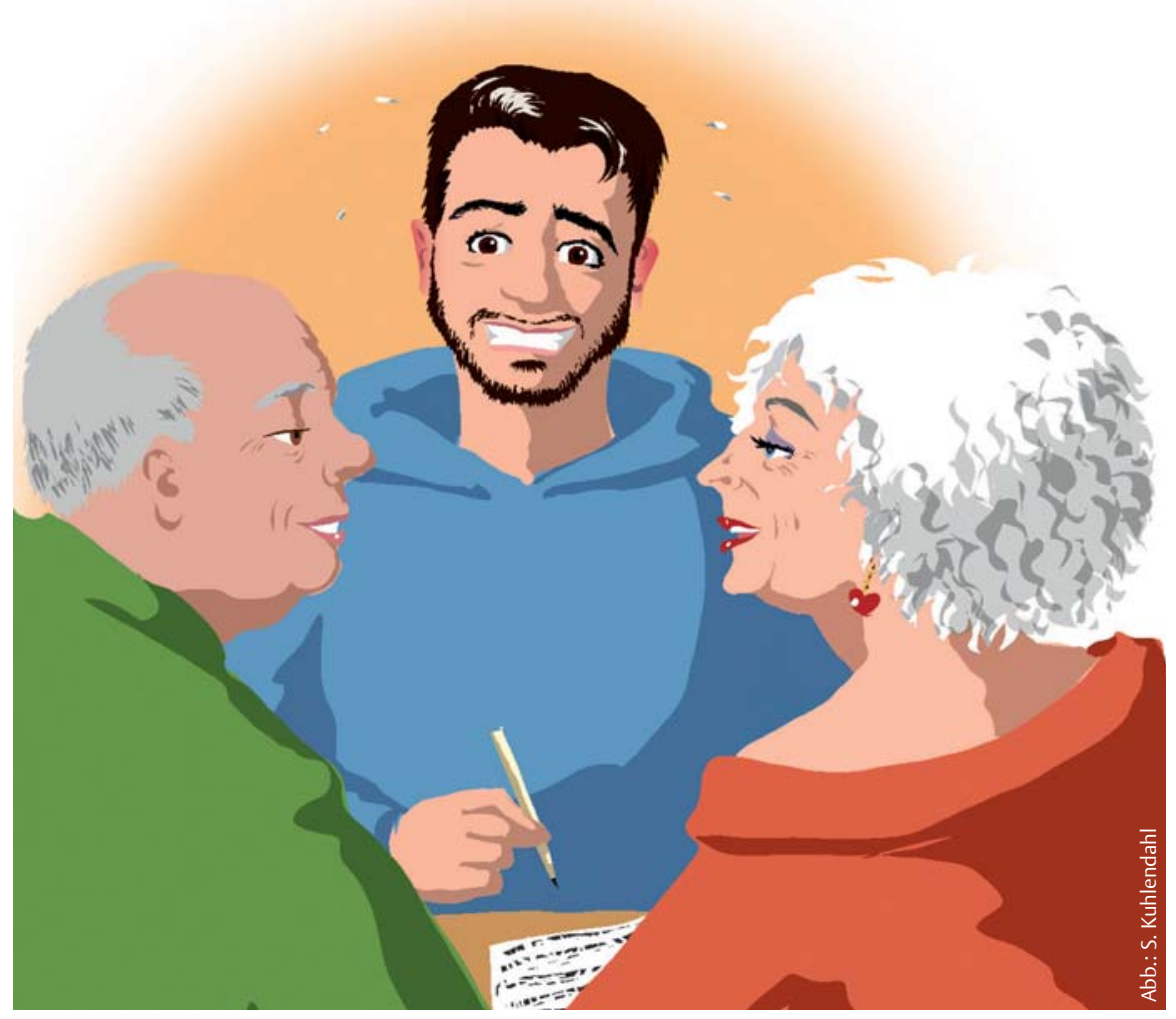

\section{Kolumne Moderne Ergotherapie ist betätigungsorientiert und richtet sich nach den individuellen Anliegen der Klienten. Natürlich alltagsnah, das versteht sich für Vollprofi Michael Schiewack von selbst. Hin und wieder kommt aber auch er an seine Grenzen ...}

Professionell und immer auf der Höhe der Zeit. In meiner Praxis ist das mein Mantra. Außerdem therapiere ich so, dass sich die Klienten mit ihren persönlichen Zielen angenommen fühlen. Darauf trinke ich eine Tasse Tee. Ich beende meine Yoga-Ruhe, da sich ein neuer Klient angekündigt hat: ein Herr, Ende 60, Schlaganfall. Souverän bereite ich meine Unterlagen für eine moderne, betätigungsorientierte und klientenzentrierte Vorgehensweise vor.

Der Klient kommt in Begleitung seiner Frau. Dass auch der erweiterte Klient partizipiert, freut mich sehr. Denn auch dessen Bedürfnisse sollten wir in der Ergotherapie berücksichtigen.
Das weiß ich genau. Kaum haben beide Platz genommen, möchte die Ehefrau loslegen. Dem Mann scheint das unangenehm zu sein. Ich verstehe das. Beruhigend hebe ich die Hände. Wir Männer zwinkern uns zu. Und dann erläutere ich erst einmal, was Ergotherapie überhaupt leisten kann. Ich berichte, dass uns die individuellen Bedürfnisse und die Zufriedenheit der Klienten wichtig sind. Damit seien relevante Aktivitäten im Alltag der Klienten gemeint. In der Ergotherapie könne man genau daran arbeiten, sodass der Klient und wenn möglich auch sein Umfeld eine hohe Zufriedenheit erfahren. Die Ehefrau lächelt und nickt. Begeistert setzt sie schon wieder an, doch ihr Mann schaut verschämt auf den Boden. Ich bin noch nicht fertig, bremse sie, hole meinen COPM-Bogen heraus und erläutere das Vorgehen. Dazu erwähne ich, dass nach kurzer Rücksprache mit und Rezeptänderung durch den Arzt auch Hausbesuche möglich seien. Denn dort könne ich effizienter die Handlung nachvollziehen, analysieren und Lösungen vor Ort generieren - mithilfe von Beratung, Coaching oder Einüben. Als Ergo-Profi biete ich zudem eine Videoanalyse als Vorher-nachher-Vergleich an. Das habe ich schließlich kürzlich in der ergopraxis gelesen.

Der Klient lehnt sich zurück. Seine Frau auch. Beide lächeln erst sich an, dann mich und meinen, dass sie sich schon jetzt sehr gut aufgehoben fühlen und sich sicher sind, dass ich ihnen helfen werde. Ich fühle mich mal wieder in der Anwendung von Modellen und deren Assessments bestätigt. Die Frau ergreift das Wort: „Wissen Sie, wir waren immer sehr aktiv.“ Ich nicke verständnisvoll. Sie scheint es nicht mehr auszuhalten und will endlich ihre Bedürfnisse loswerden. Ich lasse sie gewähren. Sie legt los: „Wissen Sie, gern würden wir das Angebot des Hausbesuchs annehmen. Wir werden uns selbst um die Änderung des Rezeptes kümmern. Wir waren schon immer sehr aktiv als Paar." Sie lächelt mich an. Ich versuche, professionell zu wirken. „Was uns wichtig ist, können wir in der Performance mit einer klaren Zwei bewerten, die Zufriedenheit liegt bei Drei.“ Beeindruckt notiere ich das. Nun warte ich auf die Aktivität. „Wir haben leidenschaftlich gerne Sex miteinander. Und die Performance, wie Sie sie so schön nennen, ist unser Problem.“

Mir läuft es eiskalt den Rücken herunter. Ich schlucke und schaue den Mann betreten an. Dieser wirkt gelöst und lächelt. Ich starre auf den COPM-Bogen, versuche, etwas zu notieren, und stottere vor mich hin: „Ähmmm ... das Ausziehen könnten wir in den Bereich der Selbstversorgung einordnen ... den Akt vielleicht bei Produktivität ... oder eher Freizeit?“ Die Ehefrau steht auf: „Ich freue mich, dass Sie so offen sind und unsere Wünsche berücksichtigen. Ergotherapie war mir vorher eher suspekt. Aber mit Ihren Erläuterungen fühlen wir uns bei Ihnen genau richtig. Wir sehen uns dann also nächste Woche bei uns zu Hause.“

Jetzt bin ich es, der mechanisch nickt. In welchem Modell finde ich wohl heraus, wie ich mich dieser Aufgabe widmen kann? Darauf erst mal eine Tasse Yogi-Tee.Michael Schiewack 